\title{
Watershed and Hydrodynamic Modeling for Evaluating the Impact of Land Use Change on Submerged Aquatic Vegetation and Seagrasses in Mobile Bay
}

\author{
Authors: Maurice G. Estes, Jr., Mohammad Al-Hamdan, Ron Thom, Dale Quattrochi, Dana \\ Woodruff, Chaeli Judd, Jean Ellis, Brian Watson, Hugo Rodriguez, and Hoyt Johnson
}

There is a continued need to understand how human activities along the northern Gulf of Mexico coast are impacting the natural ecosystems. The gulf coast is also experiencing rapid population growth and associated land cover/land use change. Mobile Bay, AL is a designated pilot region of the Gulf of Mexico Alliance (GOMA) and is the focus area of many current NASA and NOAA studies, for example. This is a critical region, both ecologically and economically to the entire United States because it: has the fourth largest freshwater inflow in the continental USA, is a vital nursery habitat for commercially and recreational important fisheries, and houses a working waterfront and port that is expanding. The gulf coast is also experiencing rapid population growth and associated Land cover/land use change.

Watershed and hydrodynamic modeling has been performed for Mobile Bay to evaluate the impact of land use change in Mobile and Baldwin counties on the aquatic ecosystem. Watershed modeling using the Loading Simulation Package in C++ (LSPC) was performed for all watersheds contiguous to Mobile Bay for land use Scenarios in 1948, 1992, 2001, and 2030. The Prescott Spatial Growth Model was used to project the 2030 land use scenario based on observed trends. All land use scenarios were developed to a common land classification system developed by merging the 1992 and 2001 National Land Cover Data (NLCD). The LSPC model output provides changes in flow, temperature, sediments and general water quality for 22 discharge points into the Bay. Theses results were inputted in the Environmental Fluid Dynamics Computer Code (EFDC) hydrodynamic model to generate data on changes in temperature, salinity, and sediment concentrations on a grid with four vertical profiles throughout the Bay's aquatic ecosystems. The models were calibrated using in-situ data collected at sampling stations in and around Mobile bay. This phase of the project has focused on sediment modeling because of its significant influence on light attenuation which is a critical factor in the health of submerged aquatic vegetation. The impact of land use change on sediment concentrations was evaluated by analyzing the LSPC and EFDC sediment simulations for the four land use scenarios. Such analysis was also performed for storm and non-storm periods. Insitu data of total suspended sediments (TSS) and light attenuation were used to develop a regression model to estimate light attenuation from TSS. This regression model was used to derive marine light attenuation estimates throughout Mobile bay using the EFDC TSS outputs.

The changes in sediment concentrations and associated impact on light attenuation in the aquatic ecosystem were used to perform an ecological analysis to evaluate the impact on seagreasses and Submerged Aquatic Vegetation (SAV) habitat. This is the key product benefiting the Mobile Bay coastal environmental managers that integrates the influences of sediments due to land use driven flow changes with the restoration potential of SAVs.

This project is a collaborative effort between NASA Marshall Space Flight Center, Universities Space Research Association, NASA Stennis Space Center, Battelle at the Pacific Northwest National Laboratory, Tetra Tech Engineering, and Prescott College. 


\title{
Watershed and Hydrodynamic Modeling for Evaluating the Impact of Land Use Change on Submerged Aquatic Vegetation and Seagrasses in Mobile Bay
}

Authors: ${ }^{1}$ Maurice G. Estes, Jr., ${ }^{1}$ Mohammad Al-Hamdan, ${ }^{3}$ Ron Thom, ${ }^{2}$ Dale Quattrochi, ${ }^{3}$ Dana Woodruff, ${ }^{3}$ Chaeli Judd, ${ }_{4}^{4}$ Jean Ellis, ${ }^{5}$ Brian Watson, ${ }^{5}$ Hugo Rodriguez, and ${ }^{6}$ Hoyt Johnson

${ }^{1}$ Universities Space Research Association and ${ }^{2}$ Marshall Space Flight Center

NSSTC

320 Sparkman Drive

Huntsville, AL 35805

${ }^{3}$ Pacific Northwest National Laboratory

1529 W. Sequim Bay Rd.

Sequim, WA 98382

${ }^{4}$ University of South Carolina

Columbia, SC

${ }^{5}$ Tetra Tech Engineering

Atlanta, GA

${ }^{6}$ Prescott College

Prescott, AZ

\begin{abstract}
There is a continued need to understand how human activities along the northern Gulf of Mexico coast are impacting the natural ecosystems. The gulf coast is experiencing rapid population growth and associated land cover/land use change. Mobile Bay, AL is a designated pilot region of the Gulf of Mexico Alliance (GOMA) and is the focus area of many current NASA and NOAA studies, for example. This is a critical region, both ecologically and economically to the entire United States because it has the fourth largest freshwater inflow in the continental USA, is a vital nursery habitat for commercially and recreational important fisheries, and houses a working waterfront and port that is expanding. Watershed and hydrodynamic modeling has been performed for Mobile Bay to evaluate the impact of land use change in Mobile and Baldwin counties on the aquatic ecosystem. Watershed modeling using the Loading Simulation Package in C++ (LSPC) was performed for all watersheds contiguous to Mobile Bay for land use Scenarios in 1948, 1992, 2001, and 2030. The Prescott Spatial Growth Model was used to project the 2030 land use scenario based on observed trends. All land use scenarios were developed to a common land classification system developed by merging the 1992 and 2001 National Land Cover Data (NLCD). The LSPC model output provides changes in flow, temperature, sediments and general water quality for 22 discharge points into the Bay. These results were inputted in the Environmental Fluid Dynamics Computer Code (EFDC) hydrodynamic model to generate data on changes in temperature, salinity, and sediment concentrations on a grid with four vertical profiles throughout the Bay's aquatic ecosystems. The models were calibrated using in-situ data collected at sampling stations in and around Mobile bay. This phase of the project has focused on sediment modeling because of its significant influence on light attenuation which is a critical factor in the health of submerged aquatic vegetation. The impact of land use change on sediment concentrations was evaluated by analyzing the LSPC and EFDC sediment simulations for the four land use scenarios. Such analysis was also performed for storm and non-storm periods. In- situ data of total suspended sediments (TSS) and light attenuation were used to develop a regression model to estimate light attenuation from TSS. This regression model was used to derive marine light attenuation estimates throughout Mobile bay using the EFDC TSS outputs.
\end{abstract}

The changes in sediment concentrations and associated impact on light attenuation in the aquatic ecosystem were used to perform an ecological analysis to evaluate the impact on seagreasses and Submerged Aquatic Vegetation (SAV) habitat. This is the key product benefiting the Mobile Bay coastal environmental managers that integrates the influences of sediments due to land use driven flow changes with the restoration potential of SAVs.

This project is a collaborative effort between NASA Marshall Space Flight Center, Universities Space Research Association, NASA Stennis Space Center, Battelle at the Pacific Northwest National Laboratory, Tetra Tech Engineering, and Prescott College. 


\section{Background}

Mobile Bay and the surrounding watersheds provide essential habitat and biodiversity for the Gulf of Mexico ecosystem. It is a vital nursery habitat for several commercially and recreational important fish species and comprises the fourth largest freshwater inflow in contiguous US (Stout, 1998). This region's population is rapidly growing, as is the working waterfront and port. The Gulf of Mexico Research Requirements Planning Workshops conducted in MS and AL identified this region as a priority area. Thus, the proposed project was chosen to take place in and around Mobile Bay, AL because of the estuary's critical role in the Gulf of Mexico system and the contiguous United States.

Over the past century more than half of coastal and estuarine wetlands and shallow water habitats have disappeared (Dahl 1990). These coastal wetlands provide critical storm attenuation capacity, protecting human life and interests as well as crucial ecological resources to support fisheries, and multiple chemical and physical processes. Today, remaining wetlands face uncertain futures with multiple sources of stress both anthropogenic and climatic in nature.

As development and other activities increase in coastal watersheds, there is a shift not only in how and when run-off reaches rivers and bays, but also in the temperature and the total amount of sediment carried. Even small changes in physical and chemical regimes can detrimentally impact nearshore environments. For example, seagrasses and other types of submerged aquatic vegetation (SAV) depend on specific habitat characteristics for survival. Light is of critical importance. Changes in landuse in coastal watersheds have had significant impacts SAV distribution and health (Orth et al. 2006).

\section{Overview of Methodology}

Watershed and hydrodynamic modeling was performed in Mobile Bay to evaluate the impact of land use change in Mobile and Baldwin counties on the aquatic ecosystem. Watershed modeling using the Loading Simulation Package in C++ (LSPC) was performed for all watersheds contiguous to Mobile Bay for land use Scenarios in 1948, 1992, 2001, and 2030. The Prescott Spatial Growth Model was used to project the 2030 land use scenario based on observed trends. All land use scenarios were used? a common land classification system developed by merging the 1992 and 2001 National Land Cover Data (NLCD). The LSPC model output provides changes in flow, temperature, sediments and general water quality for 22 discharge points into the Bay. These results were inputted in the Environmental Fluid Dynamics Computer Code (EFDC) hydrodynamic model to generate data on changes in temperature, salinity, and sediment concentrations on a grid with four vertical profiles throughout the Bay's aquatic ecosystems. The models were calibrated using in-situ data collected at sampling stations in and around Mobile bay. This phase of the project has focused on sediment modeling because of its significant influence on light attenuation which is a critical factor in the health of submerged aquatic vegetation. The impact of land use change on sediment concentrations was evaluated by analyzing the LSPC and EFDC sediment simulations for the four land use scenarios. Such analysis was also performed for storm and non-storm periods. In- situ data of total suspended sediments (TSS) and light attenuation were used to develop a regression model to estimate light attenuation from TSS. This regression model was used to derive marine light attenuation estimates throughout Mobile bay using the EFDC TSS outputs. The changes in sediment concentrations and associated impact on light attenuation in the aquatic ecosystem were used to perform an ecological analysis to evaluate the impact on seagreasses and SAV habitat. This is the key product benefiting the Mobile Bay coastal environmental managers that integrates the influences of sediments due to land use driven flow changes with the restoration potential of SAVs.

\section{Model descriptions}

The Prescott Spatial Growth Model (PSGM) is an Arc geographic information system (GIS) compatible application that allocates future growth into available land based on user-defined parameters. The purpose of the PSGM is to help users develop alternative future patterns of LCLU based on socio-economic projections such as population, employment and other controlling factors. When creating scenarios based on future development, the PSGM requires several inputs. Developable land must be provided as an input grid that represents areas suitable for accepting future growth. Growth projections quantify the demand for land area to be developed for each time horizon for each LCLU type. These projections are derived from socio-economic drivers using a PSGM utility that determines the growth for each urban LCLU category (industrial, high-density residential, etc.). Suitability rules for location of future growth are specified using a PSGM table interface. When the PSGM runs, it allocates the new growth onto the developable land grid, in the order of most to least suitable land. The output of the PSGM is a series of growth grids, one for each time step and LCLU type, showing the anticipated future growth pattern.

The Loading Simulation Program in C++ (LSPC) is a watershed modeling system that includes streamlined Hydrologic Simulation Program Fortran (HSPF) algorithms for simulating hydrology, sediment, and general water quality on land, as well as a simplified stream transport model. The model uses a Microsoft Access database to manage model data including LCLU scenarios and weather text files for driving the simulation. For each model run, it automatically generates comprehensive text-file output by sub-watershed for all land-layers, reaches, and simulated modules, which can be expressed on hourly or daily intervals. 
Output from LSPC has been linked to other model applications, including the EFDC hydrodynamic model proposed for this project (ERD, 2007).

The Environmental Fluid Dynamics Code (EFDC) is a state-of-the-art hydrodynamic model that can be used to simulate aquatic systems in one, two, and three dimensions (ERD, 2007). EFDC uses stretched or sigma vertical coordinates and Cartesian or curvilinear, orthogonal horizontal coordinates to represent the physical characteristics of a water body. The EFDC can simulate water temperature, salinity, and total suspended sediment throughout a water body.

The GIS based habitat suitability model, was created during the pilot project phase to predict suitable habitats for different species of submerged aquatic vegetation (SAV) (Judd et al. 2007). This spatially explicit GIS model is based on known factors limiting SAV growth and evaluates three of the most important of those: desiccation, temperature, and available light. Currently, as part of Mobile Bay Modeling and Regional Sediment project, the model is utilizing total suspended sediment output as a surrogate for light attenuation to evaluate turbidity impacts on SAV health. The Model comprises three sub-models that: 1) calculate light at the depth of SAV and recodes the imagery in ranges based on available light, 2) recodes the grid in ranges based on sea surface temperature, salinity and known limitations for the species, and 3) evaluates distribution and recodes the grid based on desiccation potential. These three grids are combined in a simple map algebra subroutine for a scored grid of habitat suitability. The final output is a scored grid with values corresponding with the suitability of habitat for SAV.

\section{Study area}

In this study, we have focused only on the Mobile Bay neighboring watersheds in Mobile and Baldwin Counties, AL. Figure 1 shows the study area, modeling grid, as well as the current SAV distribution.

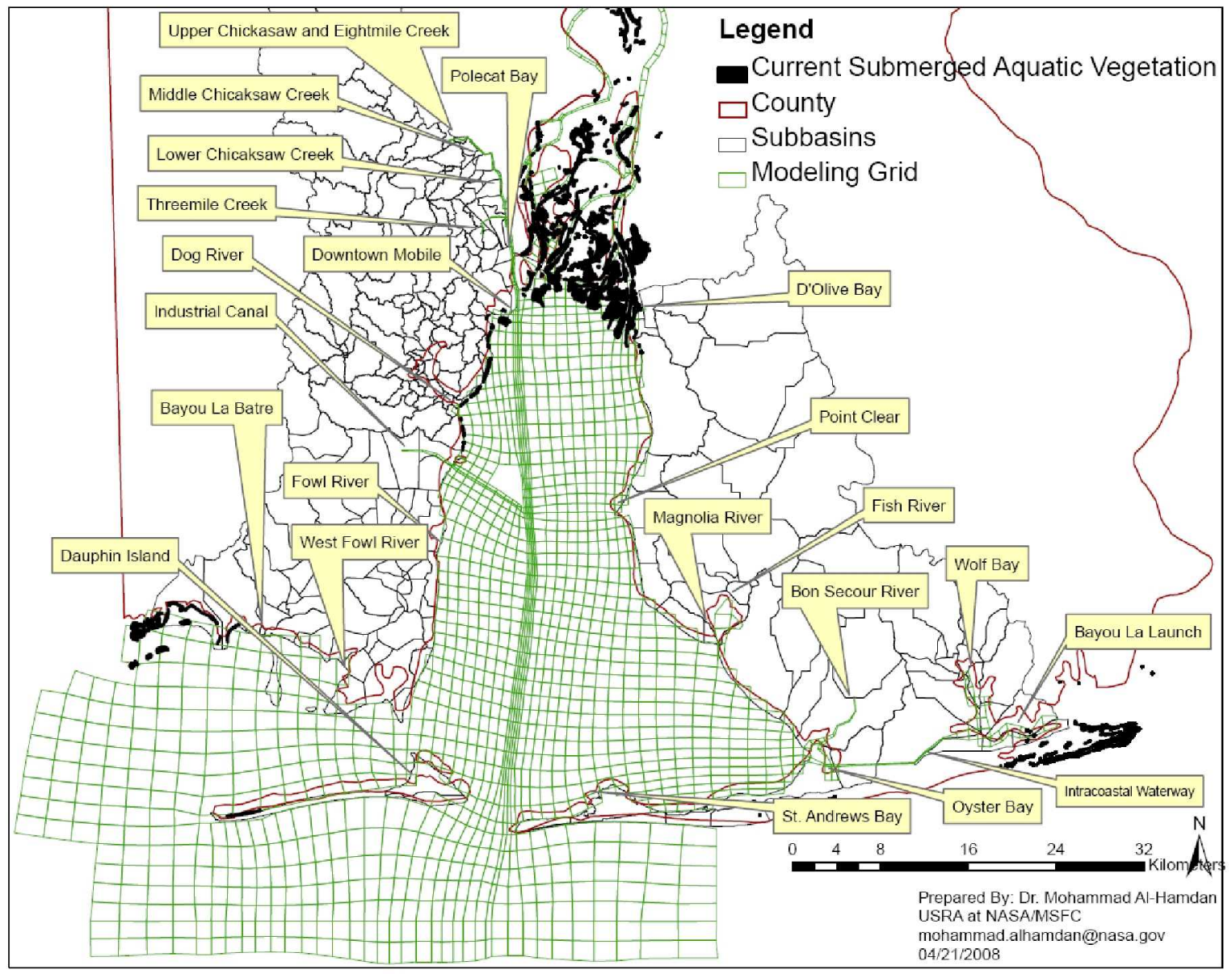

Fig. 1 Study area, modeling grid and current SAV distribution 


\section{Preliminary Results}

1992 and 2001 Landsat derived National Land Cover Data (NLCD) were used for Mobile and Baldwin Counties to determine recent historical trends and to serve as baseline land use input data for spatial growth modeling and as inputs in watershed and hydrodynamic models. A remapping of the 1992 and 2001 NLCD classes to a common classification scheme allowed for comparison for 1992 to 2001 period and future land use projection scenarios. The results of the urban growth analysis show projected growth around the Mobile metropolitan area and along major roads and highways (Figure 2).

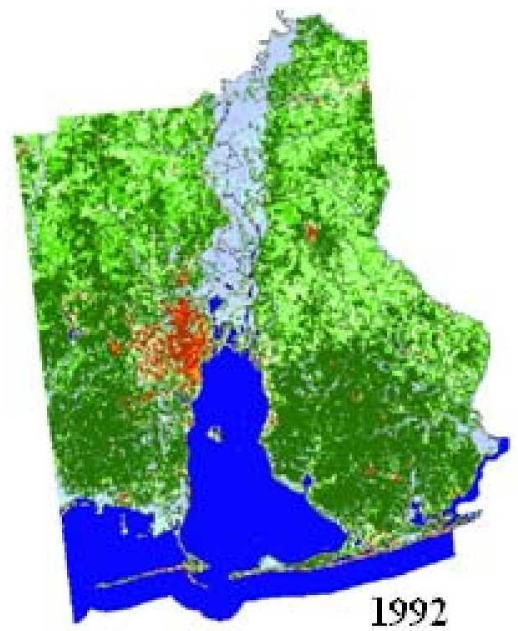

(a)

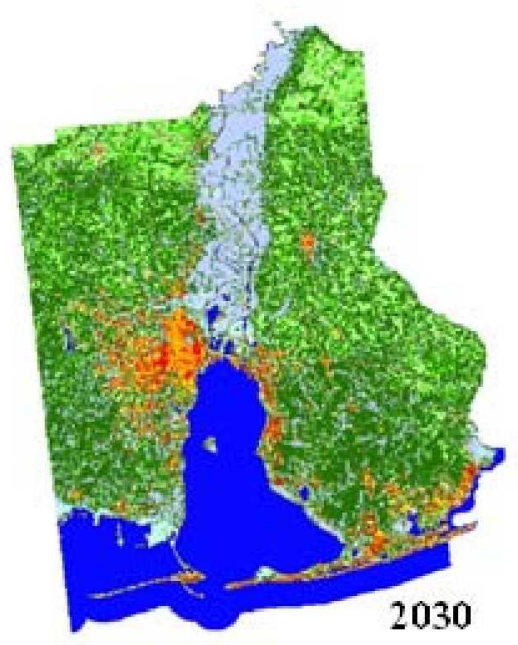

(b)
Water

Low Intensty Residential / Rec

Med/High Density Residential
Urban Commercial Bare Soil/ Transitional Deciduous Forest:
Evergreen Forest Mixed Forest / Shrub

Agricultural / Pasture
Woody Wetlands

Energent Herbaceous Wetlands

Fig 2. LCLU classifications for (a) 1992 and (b) 2030 projection

Watershed modeling was carried out to help understand the impact of the projected urban development activities on the inland water systems. The LSPC model was used for simulating hydrology and sediments. This modeling work in the Mobile Bay watershed has focused on counties adjacent to the Bay's shoreline and has found a significant impact on freshwater flows into the Bay from land use change. Land use scenarios were developed in 1992, 2001, and 2030 using the spatial growth model to evaluate impacts of flows into Mobile Bay from adjacent sub-basins. In addition, a map of 1948 land cover was used to represent a "green" pre-development scenario. All variables except land use were held constant for each model run. Overall results indicated that LCLU change to a more urban environment increases freshwater flows into Mobile Bay (Figure 3) and decreases sediments (Figure 4). Positive numbers indicate TSS was higher in the projected 2030 LCLU than 1948 and negative numbers that TSS was higher in 1948 than 2030. Also, sediment loads and delivery to the hydrologic system are significantly impacted by the duration and intensity of rainfall events. 


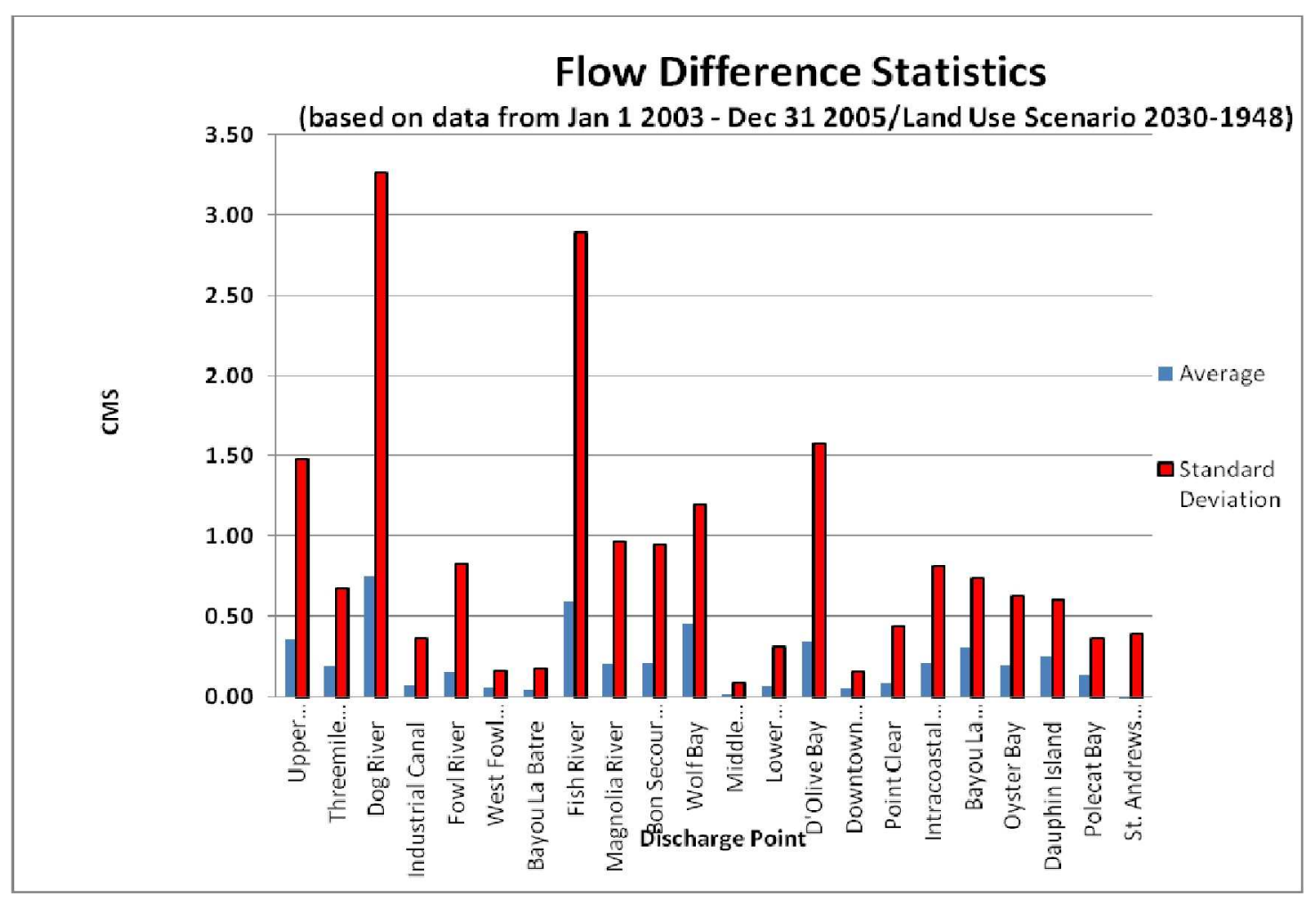

Fig. 3. Flow differences per discharge point from the watershed model

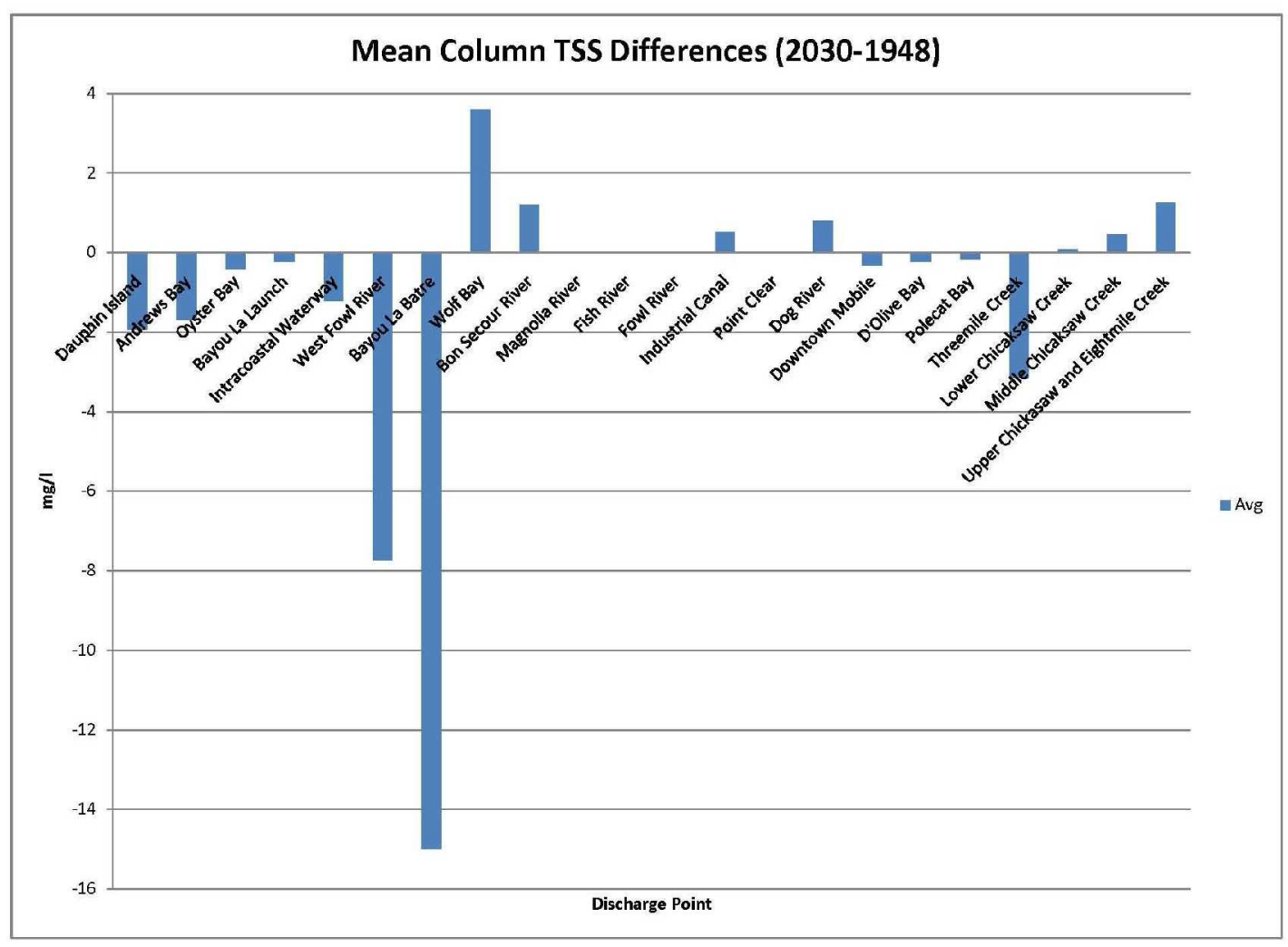

Fig 4. Mean TSS differences per discharge point from the hydrodynamic model 
The EFDC was used in this demonstration project to generate salinity and temperature outputs on a 1-2 km grid throughout Mobile Bay for different Land Cover-Land Use (LCLU) change scenarios. The EFDC water flow inputs at discharge points around the Bay come from the LSPC watershed model outputs which depend primarily on weather (i.e. precipitation and temperature) and LCLU data. The salinity, temperature, and TSS data were outputted from the EFDC for 4 vertical layers for each 1-2 km grid cell throughout the bay as demonstrated in Figure 1. The results from of this demonstration project, which has focused only on the LCLU change in Mobile Bay neighboring watersheds in Mobile and Baldwin Counties, Alabama, have shown that the changes in LCLU between 1948 and 1992; 1992 and 2001; and between 1992 and 2030 for a fixed weather data set caused statistically significant changes in temperature, salinity, and TSS throughout the Mobile Bay grid (Figures 5-6). The changes in salinity and temperature between 1948 and 1992 were the highest among the three land cover simulations, while the changes in salinity and temperature between 1992 and 2030 were higher than those between 1992 and 2001.

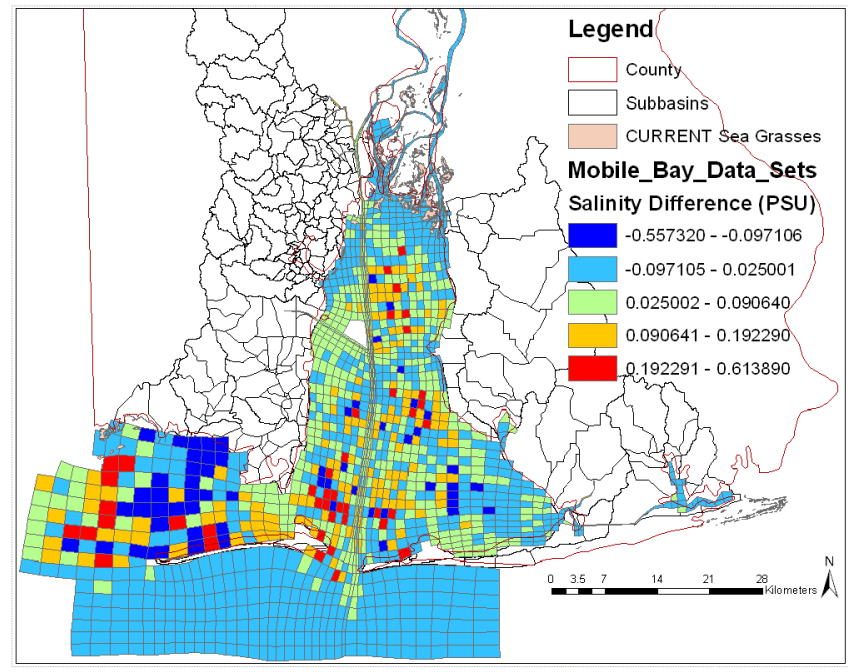

(a)

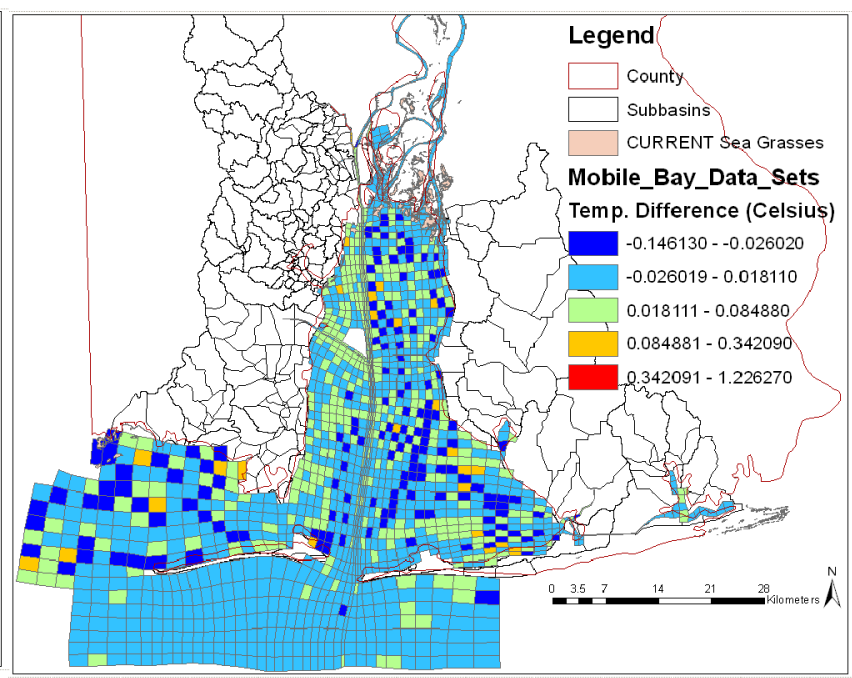

(b)

Fig 5. Average differences in salinity (PSU) (a) and temperature $\left({ }^{\circ} \mathrm{C}\right)(\mathrm{b})$ due to LCLU change between 1992 and 2001 using May 2005 weather data

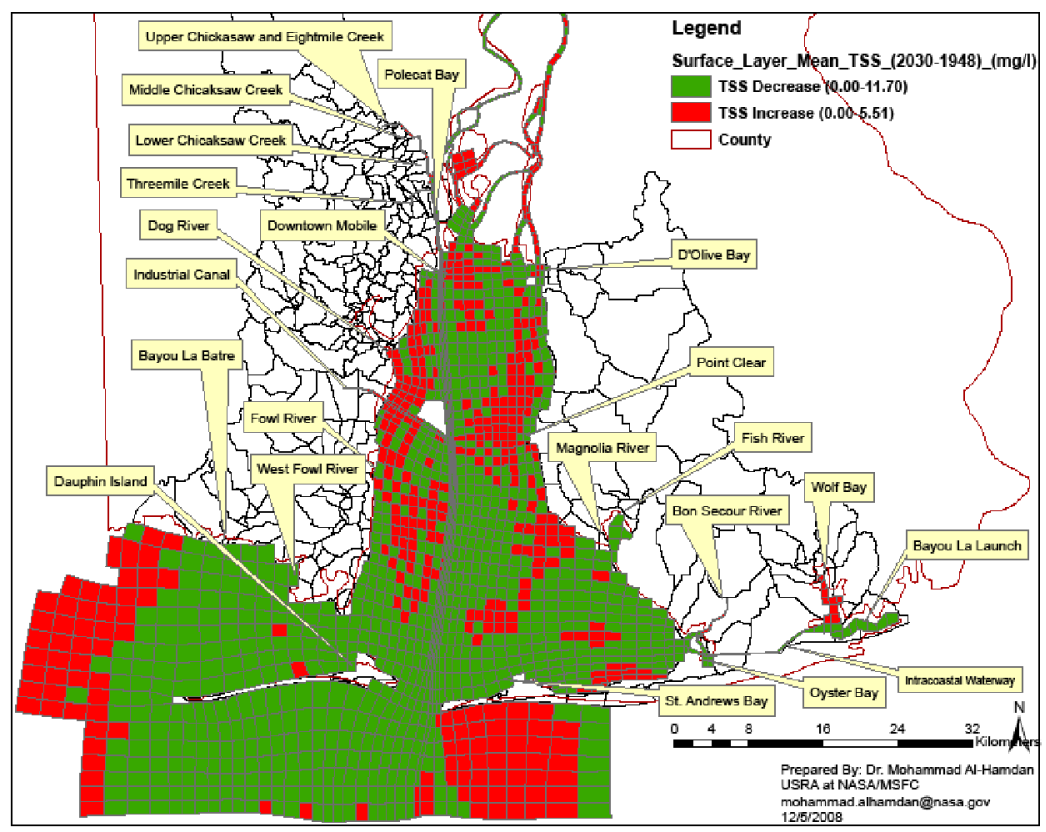

Figure 6: Areas of sediment increases and decreases Applications 


\section{Applications}

An ecological analysis is being performed to evaluate the impact of temperature, salinity, and TSS changes due to LCLU change on sea grasses and Submerged Aquatic Vegetation (SAV) habitat. This is the key product benefiting the Mobile Bay coastal resource managers that integrates the influences of temperature, salinity and TSS due to land use driven flow changes with the restoration potential of SAVs. This helps to predict potential shifts of shallow water habitats over time, thus identifying areas of resilience or marginalization, and areas that need protection, restoration or conservation measures.

This project proposes to enhance decision-making for coastal habitat restoration resource managers in two ways. First, it will provide coastal resource managers in the Gulf of Mexico with NASA-derived data products about the effect of land use and hydrologic induced changes on aquatic ecosystem health to support regional restoration coordination and decision-making. The Mobile Bay NEP will use the results of the linked spatial growth, watershed, hydrodynamic, and habitat suitability models to help identify the most optimal sites for conservation and restoration projects, and to help guide activities supported under their Fish River Watershed and Weeks Bay National Estuarine Research Reserve Planning project. Currently coastal managers at the Mobile Bay NEP and in the broader Gulf of Mexico lack access to this type of science-based guidance for restoration activities.

Secondly, the proposed project will enrich the primary databases that house environmental data for the Gulf of Mexico. These databases will include NOAA's National Coastal Data Development Center (NCDDC) Regional Ecosystem Data Management (REDM), and the Mississippi-Alabama Habitat Database, supported by Mobile Bay NEP and Dauphin Island Sea Lab (DISL).

Future research applications will focus on climate change impacts in both the hydrologic system and aquatic ecosystems. Coastal and estuarine wetland and shallow water habitats are driven by tidal dynamics and elevation. They are distributed, limited, and altered by micro-topographic changes. Species association in a wetland may shift with changes in inches in the topography. In the Gulf of Mexico, subsiding wetlands may be a good indicator of some of the effects that will be seen in sea level rise. Subsidence by just a few inches have caused shifts in vegetation from former marshes to seagrasses in some areas (King and Sheridan 2006), and loss of salt marshes in others (Morton et al. 2003). However, the question is more complex. Species distribution is often limited by tidal hydrodynamics, including the frequency of inundation, the depth of inundation and the amount of freshwater reaching the plants. All climate change scenarios have predicted, in addition to a base rate of sea level rise, a change in intensity of extreme events and freshwater delivery (IPCC 2007). These changes in frequency and duration of water delivery are equally important to understand how species may shift over time.

\section{References}

[1] Dahl, Thomas E. 1990. Wetlands losses in the United States 1780's to 1980's. U.S. Department of the Interior, Fish and Wildlife Service, Washington, D.C. Jamestown, ND: Northern Prairie Wildlife Research Center Online.

http://www.npwrc.usgs.gov/resource/wetlands/wetloss/index.htm

[2] Judd KS, C Judd, JA Engel-Cox, T Gulbransen, MG Anderson, DL Woodruff, RM Thom, M Guzy, D Hardin, and M Estes. 2007b. Gulf of Mexico Regional Collaborative Final Report. PNNL-17180, Pacific Northwest National Laboratory, Richland, WA

[3] King, S. P., and P. Sheridan. 2006. Nekton of new seagrass habitats colonizing a subsided salt marsh in Galveston Bay, Texas. Estuaries and Coasts 29, no. 2: $286-96$

[4] IPCC, 2007: Climate Change 2007: Synthesis Report. Contribution of Working Groups I, II and III to the Fourth Assessment Report of the Intergovernmental Panel on Climate Change. Pachauri, R.K and Reisinger, A. (eds.). IPCC, Geneva, Switzerland, p 104.

[5] Morton, R., G. Tiling, and N. Ferina. 2003. Primary Causes of Wetland Loss at Madison Bay, Terrebonne Parish, Louisiana, 03-60. U.S. Geological Survey, Center for Coastal and Watershed Studies, St. Petersburg, FL.

[6] Stout, J.P., Heck, K.L. Jr., Valentine, J.F., Dunn, S.J., Spitzer, P.M. 1998. Preliminary Characterization of Habitat Loss: Mobile Bay National Estuary Program. Dauphin Island, AL. 213pp.

[7] Orth RJ. Carruthers TJB, Dennison WC, Duarte CM, Fourqurean JW, Heck KL, Hughes AR, Kendrick GA, Kenworthy WJ, Olyarnik, S, Short FT, Waycott M, Williams SL (2006). A global crisis for seagrass ecosystems. Bioscience 56 (12); 987-96. 